\title{
DEFORMATION OF SUBGLACIAL SEDIMENTS AND ITS IMPLICATIONS
}

\section{(Abstract only)}

by

\author{
G. S. Boulton
}

(School of Environmental Sciences, University of East Anglia, Norwich NR4 7TJ, England)

\section{ABSTRACT}

Field experiments have shown that unlithified sediments beneath a glacier may undergo strong shear deformation in response to the movement of the overlying glacier, and that much of the forward movement of the glacier may be contributed by this mechanism. Mathematical analysis of the physics of this process suggests that it can be very important in glaciers underlain by deformable sediments.

Two- and three-dimensional patterns of subglacial sediment deformation are analysed in response to both irregularities on a sub-sediment rock bed and grain-size inhomogeneities within the sediment itself. The results of a modelling exercise show that drumlin fields may develop from subglacial deformation and that the form and size of the drumlin depend primarily on ice velocity, effective stress, sediment strength properties, and time.

Characteristic structures are described which are believed to reflect this process, and allow it to be recognized in areas of Quaternary glaciation.

Subglacial sediment deformation has an important effect on glacier dynamics, and icesheet reconstructions using this as a boundary condition are presented for the Laurentide and European ice sheets at $20 \mathrm{ka} \mathrm{BP}$. 